\title{
Hemoglobin Level Variability: Anemia Management among Variability Groups
}

\author{
David T. Gilbertson $^{\mathrm{a}} \quad$ Yi Peng $^{\mathrm{a}} \quad$ Brian Bradbury $^{\mathrm{b}}$ James P. Ebben ${ }^{\mathrm{a}}$ \\ Allan J. Collins ${ }^{a, c}$ \\ ${ }^{a}$ Chronic Disease Research Group, Minneapolis Medical Research Foundation, Minneapolis, Minn., \\ ${ }^{b}$ Department of Biostatistics \& Epidemiology, Amgen, Inc., Thousand Oaks, Calif., and \\ ${ }^{\mathrm{C}}$ Hennepin County Medical Center and University of Minnesota, Minneapolis, Minn., USA
}

\section{Key Words}

Anemia $\cdot$ Epoetin alfa • Erythropoietin • Iron, intravenous •

Hemoglobin $\cdot$ Mortality

\begin{abstract}
Background/Aims: Hemoglobin level variability in hemodialysis patients is common, and has been associated with comorbidity, intercurrent illness, and mortality risk. We aimed to describe the influence of anemia management interventions (erythropoiesis-stimulating agents [ESAs], intravenous iron, and transfusions) on hemoglobin variability. Methods: We studied all Medicare primary payer hemodialysis patients who survived and had ESA claims in the first 6 months of 2004 ( $n=159,720$ ). Monthly hemoglobin values were categorized as low (<11 g/dl), intermediate (11-12.5 g/dl), and high ( $>12.5 \mathrm{~g} / \mathrm{dl}$ ). Variability groups were classified based on lowest and highest hemoglobin categories during a 6month observation period. ESA, intravenous iron, and transfusion use were characterized by variability group. Results: Patients with consistently low or low and intermediate hemoglobin received the highest ESA doses and the most frequent transfusions, while patients with consistently or intermittently intermediate or high hemoglobin received lower ESA doses and fewer transfusions. Intravenous iron doses were highest initially for patients with consistently high hemoglobin; these doses subsequently declined. Iron doses were lowest for patients with consistently intermediate hemoglobin. Conclusions: Anemia management protocols
\end{abstract}

describing coordinated administration of ESAs and iron may help to increase the number of patients achieving target hemoglobin levels.

Copyright $\odot 2009$ S. Karger AG, Basel

\section{Introduction}

Higher achieved hemoglobin levels have consistently been shown to be associated with lower morbidity and mortality [1-6] among hemodialysis patients. Anemia (low hemoglobin levels) is common in hemodialysis patients because of lost kidney function and resultant inability to produce endogenous erythropoietin, which is predominantly derived from the kidneys. Consequently, hemodialysis patients receive routine administration of exogenous erythropoiesis-stimulating agents (ESAs) to raise hemoglobin levels [7]. As iron is also essential to the process of hemoglobin production, hemodialysis patients also receive routine administration of concomitant iron to help raise hemoglobin levels. Administration of these medications is intended to maintain hemoglobin levels within a target range [8] and to avoid the need for blood transfusions [7]. Transfusions can also be used to elevate hemoglobin levels, but their use has steadily declined over time [9].

Recently, several studies have shown considerable variability in hemoglobin levels among hemodialysis patients [10-12], and that certain types of variability (or lack 
thereof) may be associated with increased mortality risk [13-15]. Ebben et al. [12] first characterized hemoglobin variability patterns in more than 150,000 hemodialysis patients during a 6-month period, and observed 728 of a possible 729 variability groups in the data (defined based on the pattern of hemoglobin levels $<11,11-12.5$, and $>12.5 \mathrm{~g} / \mathrm{dl}$ during the 6 consecutive months $\left[3^{6}=729\right]$ ). In a subsequent analysis, Gilbertson et al. [14], using a nearly identical cohort, evaluated the mortality risk for patients experiencing different hemoglobin variability patterns. Both analyses also examined the relationship between hemoglobin variability patterns and intercurrent events, hospitalizations, and specific patient characteristics. Using a different methodology and data source, Yang et al. [13] found an independent association between hemoglobin variability and risk of death.

To date, no study examining hemoglobin variability has described or correlated co-administration of the 3 therapies used in anemia management (ESAs, iron, transfusions) with specific variability patterns. Given the concern recently expressed by the United States Food and Drug Administration regarding hemoglobin variability in hemodialysis patients and the safe use of ESAs in anemia management, a fuller understanding of the influence of the different anemia management interventions on hemoglobin variability patterns is necessary. Moreover, characterizing the variability patterns and the influence of the different interventions for patients with more versus less comorbidity (including frequent intercurrent events and hospitalizations) is important to better understand how much hemoglobin variability is under the control of treating physicians. The primary objective of this study, therefore, was to examine co-administration of ESAs, iron, and transfusions within specific hemoglobin variability patterns among hemodialysis patients overall, and in patients with more versus less comorbidity.

\section{Methods}

\section{Study Population}

The study population included all hemodialysis patients who survived the first 6 months of 2004, had Medicare as primary payer, and had outpatient ESA claims in each of the first 6 months of $2004(n=159,720)$. This 6 -month period was considered the exposure assessment period and was used to characterize hemoglobin variability patterns, anemia management practices, and patient characteristics.

Hemoglobin Variability Categories

Methods for defining the hemoglobin variability groups have been previously described [1]. Briefly, hemoglobin levels were ob- tained from outpatient ESA claims, the only source of these data, and categorized as low ( $\mathrm{L},<11 \mathrm{~g} / \mathrm{dl})$, intermediate (I, 11-12.5 g/dl), and high $(\mathrm{H},>12.5 \mathrm{~g} / \mathrm{dl})$. A 6 -group classification system was used, based on the lowest and highest categories seen during the 6-month observation period: low-low (L-L), intermediate-intermediate (I-I), high-high (H-H), low-intermediate (L-I), intermediate-high (I-H), and low-high (L-H).

\section{Anemia Management}

Total monthly ESA dose in each month of the 6-month baseline exposure assessment period was determined from Part A outpatient ESA claims. Intravenous iron use in each month was determined from Part A outpatient and Part B physician/supplier claims. Transfusions administered in hospital or outpatient settings were identified by searching claims for packed red blood cell transfusions using the International Classification of Diseases, 9th Edition, Clinical Modification (ICD-9-CM) procedure codes 99.03 and 99.04, or Current Procedural Terminology (CPT)/ HCPCS codes P9010, P9011, P9016, P9021, P9022, P9038, P9039, P9040, and 36430.

\section{Covariates}

ICD-9-CM codes were used to identify comorbid conditions from Medicare Part A institutional and Part B physician/supplier claims, using a method previously validated for diabetes [16], but commonly used to define comorbid conditions in general. Each comorbid condition was defined as present if at least 1 inpatient, home health, or skilled nursing facility claim, or at least 2 outpatient or physician/supplier claims were found with the corresponding diagnosis. The following comorbid conditions were included: atherosclerotic heart disease, congestive heart failure, dysrhythmia, other cardiac disease (including valvular disease), cerebrovascular accident/transient ischemic attack, peripheral vascular disease, chronic obstructive pulmonary disease, cancer, gastrointestinal bleeding, liver disease, and diabetes. Information on hospital admissions and number of hospital days was obtained from the Medicare Inpatient Standard Analytical File, and on vascular access insertions and complications from Part B physician/supplier claims using CPT codes. Demographic data were obtained from the Centers for Medicare \& Medicaid Services (CMS) Medical Evidence Report (form CMS-2728), which records date of birth, sex, race, renal diagnosis, and first end-stage renal disease (ESRD) service date.

\section{Statistical Analysis}

Descriptive statistics for continuous variables (mean, standard deviation $[\mathrm{SD}]$ ) and categorical variables (count [n], percent) were used to examine patient demographic characteristics and comorbid conditions according to the 6 hemoglobin variability categories. Monthly anemia management, including total ESA dose, percent of patients receiving intravenous iron, and percent of patients receiving transfusions across the 6 hemoglobin variability categories, was described for all patients, and separately for the subgroup of 'healthier' patients. This healthier subgroup excluded all patients who were hospitalized, underwent vascular access insertion, experienced a vascular access complication, or received intravenous (i.v.) antibiotics during the exposure assessment period to remove the effect of these events on hemoglobin variability. All analyses were conducted using SAS v9.1 (Cary, N.C., USA). 


\section{Results}

In all, 159,720 hemodialysis patients met the inclusion criteria. Of these, we excluded patients with one or more hospitalizations $(\mathrm{n}=71,876)$, vascular access insertions ( $\mathrm{n}=8,758)$, or vascular access complications $(\mathrm{n}=21,208)$, or who received i.v. antibiotics ( $\mathrm{n}=8,158$ ), leaving 49,720 patients (31.1\%) in our healthier subgroup. Table 1 shows basic descriptive statistics for demographic characteristics and comorbid conditions for the overall cohort and for the healthier subgroup, by the 6 hemoglobin variability groups, and summaries of ESA, iron, and transfusion use. In the overall cohort, the lowest percentage of patients with congestive heart failure during the 6 months was in the I-I (19.3\%) group followed by the H-H (20.4\%) and I-H (22.9\%) groups. The percentage was higher in the L-I (33.4\%) and L-H (33.3\%) groups, and highest in the L-L (42.9\%) group. Consistent patterns across the 6 groups were also observed for other comorbid conditions. Compared with the overall cohort, comorbidity in the healthier subgroup was generally considerably lower.

Comparing patient distributions (overall vs. healthier) by hemoglobin variability group shows that in the healthier cohort, patient distribution in the hemoglobin variability groups shifted towards more patients in the higher hemoglobin groups. Compared with the overall population, percentages of the healthier subgroup were higher in the I-I (6.0 vs. 9.4\%), $\mathrm{H}-\mathrm{H}$ ( 2.3 vs. $3.1 \%)$, and I-H groups (31.7 vs. $39.3 \%)$, and lower in the L-L (1.4 vs. $0.7 \%)$, L-I (18.3 vs. $16.3 \%$ ), and L-H groups (40.2 vs. $31.1 \%$; fig. 1 ).

On average, patients in the L-L group received the highest ESA doses of the 6 groups in each month (fig. 2). ESA dose increased over the 6 months for patients in the $\mathrm{L}-\mathrm{L}, \mathrm{L}-\mathrm{I}$, and L-H groups, decreased for patients in the $\mathrm{H}$ $\mathrm{H}$ group, and was relatively constant for patients in the I-I, and I-H groups. Iron doses (fig. 3) were highest in months 1-3 for patients in the $\mathrm{H}-\mathrm{H}$ group, and subsequently decreased; doses were lowest in month 1 for patients in the L-L, L-I, and I-I groups, and subsequently increased. The percentage of patients receiving transfusions was highest in the L-L group (fig. 4), followed by the $\mathrm{L}-\mathrm{I}$ and L-H groups; the percentage was lowest in the $\mathrm{H}$ $\mathrm{H}$ group. The overall change in the percent of patients receiving transfusions over the 6 months was relatively constant for all groups.

Compared with all-patient groups (solid lines, fig. 24), in the healthier-patient groups (dashed lines, fig. 2-4), average ESA and iron doses were lower, and percentages of patients receiving transfusions were lower in each month. However, overall trends in anemia management

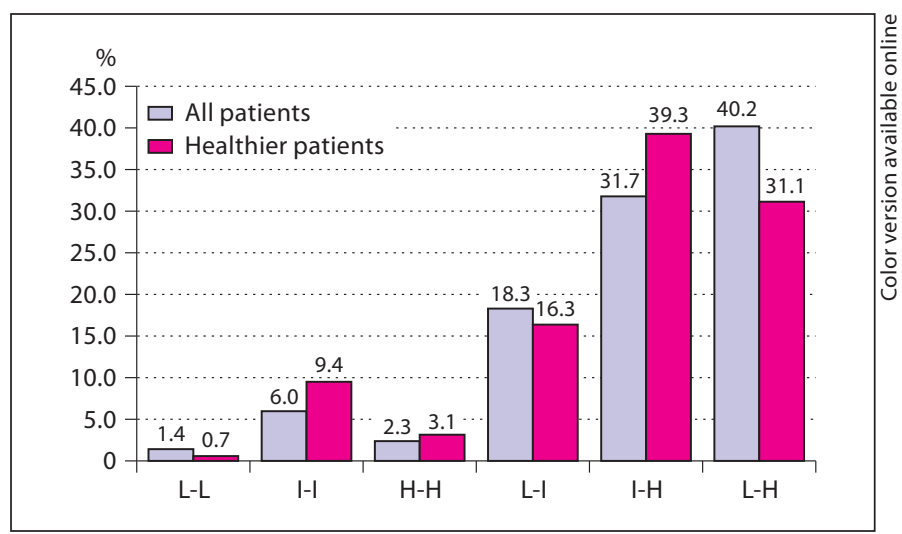

Fig. 1. Distribution of patients in hemoglobin variability groups, all patients and healthier patients with no hospitalizations, vascular access insertions, or complications during the exposure assessment period. Monthly hemoglobin values were categorized as low $(\mathrm{L},<11 \mathrm{~g} / \mathrm{dl})$, intermediate (I, 11-12.5 g/dl), and high $(\mathrm{H}$, $>12.5 \mathrm{~g} / \mathrm{dl}$ ); variability groups were classified on the basis of the lowest and highest categories seen in the 6-month observation period.

(ESA, iron, and transfusions) for healthier patients in the 6 groups over the 6 months were similar to trends for all patients.

\section{Discussion}

Our previous studies of hemoglobin variability [12, $14,15,17]$ showed that relatively few patients $(6 \%)$ are maintained in the range of $11-12.5 \mathrm{~g} / \mathrm{dl}$, and that increasing variability, and particularly increasing numbers of months with hemoglobin levels of $<11.5 \mathrm{~g} / \mathrm{dl}$, were associated with greater comorbidity burden and risk of mortality. The current study shows that some of the observed variability is removed if the population analyzed is limited to patients without hospitalizations, vascular insertions, vascular access complications, or i.v. antibiotic use; a larger percent (9 vs. $6 \%$ ) of this population was consistently within the 11-12.5 g/dl range, and a smaller percent (31 vs. $40 \%$ ) was in the L-H group. This indicates that some hemoglobin level variability is beyond the control of nephrologists and dialysis facilities.

The observed relationship between ESA dose and specific variability groups is not surprising; doses were highest (and increasing over time) for patients with consistently low hemoglobin levels, generally reflecting ESA hyporesponsiveness [18], and doses were generally lower (and decreasing) for patients with consistently high he- 
Table 1. Patient characteristics

\begin{tabular}{|c|c|c|c|c|c|c|c|c|c|c|c|c|c|c|}
\hline \multirow[b]{2}{*}{ Characteristic } & \multirow[b]{2}{*}{ All } & \multicolumn{6}{|c|}{$\begin{array}{l}\text { All patients }(\mathrm{n}=159,720)^{\mathrm{a}, \mathrm{b}} \\
\text { Hemoglobin variability group }\end{array}$} & \multirow[b]{2}{*}{ All } & \multicolumn{6}{|c|}{$\begin{array}{l}\text { Healthier patients }(\mathrm{n}=49,720)^{\mathrm{a}, \mathrm{c}} \\
\text { Hemoglobin variability group }\end{array}$} \\
\hline & & L-L & I-I & $\mathrm{H}-\mathrm{H}$ & L-I & $\mathrm{I}-\mathrm{H}$ & $\mathrm{L}-\mathrm{H}$ & & L-L & I-I & $\mathrm{H}-\mathrm{H}$ & L-I & $\mathrm{I}-\mathrm{H}$ & $\mathrm{L}-\mathrm{H}$ \\
\hline Subjects & 159,720 & 2165 & 9,646 & 3,750 & 29,222 & 50,680 & 64,257 & 49,720 & 370 & 4,676 & 1,523 & 8,129 & 19,560 & 15,462 \\
\hline \multicolumn{15}{|l|}{ Sex } \\
\hline Men & 51.3 & 53.9 & 54.1 & 56.3 & 51.0 & 52.7 & 49.5 & 55.2 & 55.9 & 56.0 & 59.8 & 54.9 & 56.4 & 53.3 \\
\hline Women & 48.7 & 46.1 & 45.9 & 43.7 & 49.0 & 47.3 & 50.5 & 44.8 & 44.1 & 44.0 & 40.2 & 45.1 & 43.6 & 46.7 \\
\hline \multicolumn{15}{|l|}{ Race } \\
\hline White & 53.4 & 48.5 & 58.4 & 51.3 & 54.7 & 53.4 & 52.4 & 52.9 & 49.2 & 57.6 & 51.3 & 54.1 & 52.4 & 51.7 \\
\hline African-American & 40.3 & 46.6 & 35.0 & 41.6 & 39.2 & 40.3 & 41.3 & 39.5 & 44.3 & 35.0 & 41.1 & 38.1 & 40.4 & 40.4 \\
\hline Other & 6.3 & 4.9 & 6.5 & 7.1 & 6.2 & 6.3 & 6.3 & 7.6 & 6.5 & 7.4 & 7.6 & 7.8 & 7.3 & 7.9 \\
\hline \multicolumn{15}{|l|}{ Age, years } \\
\hline$<40$ & 8.8 & 16.8 & 7.2 & 9.3 & 9.6 & 7.8 & 9.2 & 9.6 & 18.4 & 8.0 & 10.0 & 10.2 & 8.8 & 10.5 \\
\hline $40-64$ & 41.2 & 50.1 & 39.0 & 41.0 & 42.8 & 40.6 & 40.9 & 41.8 & 47.3 & 39.7 & 42.0 & 43.0 & 41.5 & 42.2 \\
\hline $65-74$ & 26.3 & 19.6 & 27.2 & 26.3 & 25.7 & 26.7 & 26.3 & 25.6 & 16.8 & 26.9 & 25.9 & 25.3 & 26.1 & 24.8 \\
\hline$\geq 75$ & 23.8 & 13.5 & 26.6 & 23.4 & 22.0 & 24.9 & 23.6 & 23.0 & 17.6 & 25.4 & 22.2 & 21.5 & 23.6 & 22.6 \\
\hline \multicolumn{15}{|l|}{ Cause of renal failure } \\
\hline Diabetes & 42.8 & 35.1 & 43.4 & 42.4 & 42.7 & 42.9 & 43.0 & 38.0 & 31.1 & 39.6 & 36.4 & 38.1 & 38.5 & 37.2 \\
\hline Hypertension & 29.8 & 27.3 & 28.4 & 30.3 & 28.5 & 30.5 & 30.0 & 31.6 & 26.5 & 29.7 & 32.6 & 30.2 & 32.3 & 32.2 \\
\hline Other & 27.4 & 37.6 & 28.2 & 27.3 & 28.8 & 26.6 & 27.0 & 30.3 & 42.4 & 30.8 & 31.1 & 31.7 & 29.2 & 30.6 \\
\hline \multicolumn{15}{|l|}{ Dialysis duration, years } \\
\hline$<1$ & 20.4 & 18.7 & 14.0 & 28.2 & 16.1 & 21.4 & 22.3 & 14.5 & 13.8 & 10.4 & 21.1 & 10.7 & 15.4 & 16.0 \\
\hline 1 to $<3$ & 31.5 & 27.2 & 35.9 & 27.5 & 32.2 & 31.7 & 30.8 & 32.9 & 26.5 & 36.2 & 29.7 & 33.3 & 32.9 & 32.3 \\
\hline 3 to $<5$ & 20.8 & 19.6 & 22.8 & 17.9 & 22.1 & 20.7 & 20.2 & 22.7 & 23.5 & 23.7 & 19.2 & 23.8 & 22.6 & 22.2 \\
\hline$\geq 5$ & 27.2 & 34.5 & 27.3 & 26.5 & 29.6 & 26.3 & 26.7 & 29.9 & 36.2 & 29.7 & 29.9 & 32.2 & 29.1 & 29.5 \\
\hline \multicolumn{15}{|l|}{ Comorbid conditions } \\
\hline ASHD & 31.4 & 34.9 & 24.0 & 25.4 & 34.0 & 26.8 & 35.2 & 12.8 & 10.5 & 12.7 & 13.1 & 12.9 & 12.4 & 13.2 \\
\hline $\mathrm{CHF}$ & 29.0 & 42.9 & 19.3 & 20.4 & 33.4 & 22.9 & 33.3 & 8.7 & 11.9 & 8.1 & 9.2 & 8.5 & 8.4 & 9.4 \\
\hline CVA/TIA & 10.3 & 12.1 & 6.6 & 6.9 & 11.1 & 8.2 & 12.3 & 3.3 & 2.7 & 2.7 & 3.0 & 3.2 & 3.4 & 3.5 \\
\hline PVD & 24.0 & 31.3 & 16.1 & 18.7 & 26.9 & 19.6 & 27.5 & 8.6 & 10.0 & 7.9 & 9.0 & 8.8 & 8.7 & 8.5 \\
\hline Dysrhythmia & 19.6 & 27.4 & 15.2 & 15.3 & 22.3 & 16.2 & 21.8 & 7.0 & 11.1 & 6.7 & 6.8 & 7.3 & 6.4 & 7.5 \\
\hline Other cardiac & 21.5 & 35.8 & 14.6 & 13.9 & 25.7 & 16.1 & 24.8 & 3.2 & 2.2 & 2.6 & 3.4 & 3.6 & 2.9 & 3.5 \\
\hline COPD & 12.8 & 18.0 & 8.0 & 9.3 & 15.0 & 9.8 & 14.9 & 1.3 & 2.7 & 1.0 & 0.6 & 1.5 & 1.0 & 1.6 \\
\hline GI bleeding & 6.5 & 16.3 & 2.8 & 2.8 & 8.2 & 3.6 & 8.3 & 6.5 & 7.0 & 6.7 & 5.6 & 7.3 & 6.1 & 6.6 \\
\hline Liver disease & 7.8 & 13.8 & 7.5 & 6.7 & 8.7 & 6.8 & 8.1 & 7.2 & 9.2 & 8.0 & 7.4 & 7.9 & 6.7 & 7.2 \\
\hline Cancer & 5.4 & 9.3 & 4.8 & 3.6 & 6.1 & 4.3 & 5.9 & 3.6 & 5.9 & 3.8 & 2.4 & 3.8 & 3.2 & 3.8 \\
\hline Diabetes & 54.9 & 51.1 & 53.0 & 51.7 & 55.5 & 53.6 & 56.3 & 45.1 & 37.6 & 46.6 & 42.7 & 45.1 & 45.7 & 44.3 \\
\hline ESA dose $\mathrm{d}^{\mathrm{d}}$ & 81,172 & 207,736 & 55,875 & 59,031 & 98,421 & 60,816 & 90,208 & 63,649 & 178,294 & 49,112 & 51,624 & 76,871 & 52,490 & 73,652 \\
\hline Receiving any iron & 84.1 & 71.8 & 77.1 & 87.2 & 80.6 & 84.8 & 86.4 & 78.9 & 62.7 & 72.5 & 83.9 & 73.7 & 80.8 & 81.0 \\
\hline Monthly IV iron dose, $\mathrm{mg}^{\mathrm{e}}$ & 361.2 & 397.4 & 314.1 & 367.3 & 349.1 & 350.9 & 378.1 & 336.1 & 380.2 & 298.6 & 352.8 & 324.3 & 331.7 & 353.1 \\
\hline Monthly IV iron dose, $\mathrm{mg}^{\mathrm{f}}$ & 303.8 & 285.3 & 242.2 & 320.3 & 281.4 & 297.6 & 326.7 & 266.8 & 240.3 & 218.3 & 297.8 & 241.0 & 269.3 & 288.1 \\
\hline Transfusions ${ }^{\mathrm{g}}$ & 13.1 & 121.7 & 2.7 & 1.9 & 21.6 & 3.1 & 15.8 & 1.9 & 63.8 & 0.1 & 0.1 & 2.8 & 0.2 & 2.6 \\
\hline
\end{tabular}

Values are percents unless otherwise indicated. ASHD = Atherosclerotic heart disease; $\mathrm{CHF}=$ congestive heart failure; $\mathrm{COPD}=$ chronic obstructive pulmonary disease; CVA/TIA = cerebrovascular accident $/$ transient ischemic attack; ESA = erythropoiesis-stimulating agent; GI = gastrointestinal; PVD = peripheral vascular disease.

${ }^{a}$ Monthly hemoglobin values were categorized as low ( $\left.\mathrm{L},<11 \mathrm{~g} / \mathrm{dl}\right)$, intermediate (I, 11-12.5 g/dl), and high $(\mathrm{H},>12.5 \mathrm{~g} / \mathrm{dl})$; variability groups were classified on the basis of the lowest and highest categories seen in the 6 -month observation period.

b All $\mathrm{p}$ values $<0.0001 ; \chi^{2}$ test for categorical variables and $\mathrm{F}$ test for continuous variables.
${ }^{c} \mathrm{p}$ values $<0.05$ except ASHD (0.2905), CVA/TIA (0.1372), and PVD (0.4587); $\chi^{2}$ test for categorical variables and $\mathrm{F}$ test for continuous variables.

d Average monthly units.

${ }^{\mathrm{e}}$ Monthly i.v. iron dose, limited to those receiving iron in any given month.

${ }^{\mathrm{f}}$ Monthly i.v. iron dose, including all patients; individuals who did not receive iron assigned a value of zero.

$\mathrm{g}$ Average number per 100 patients. 


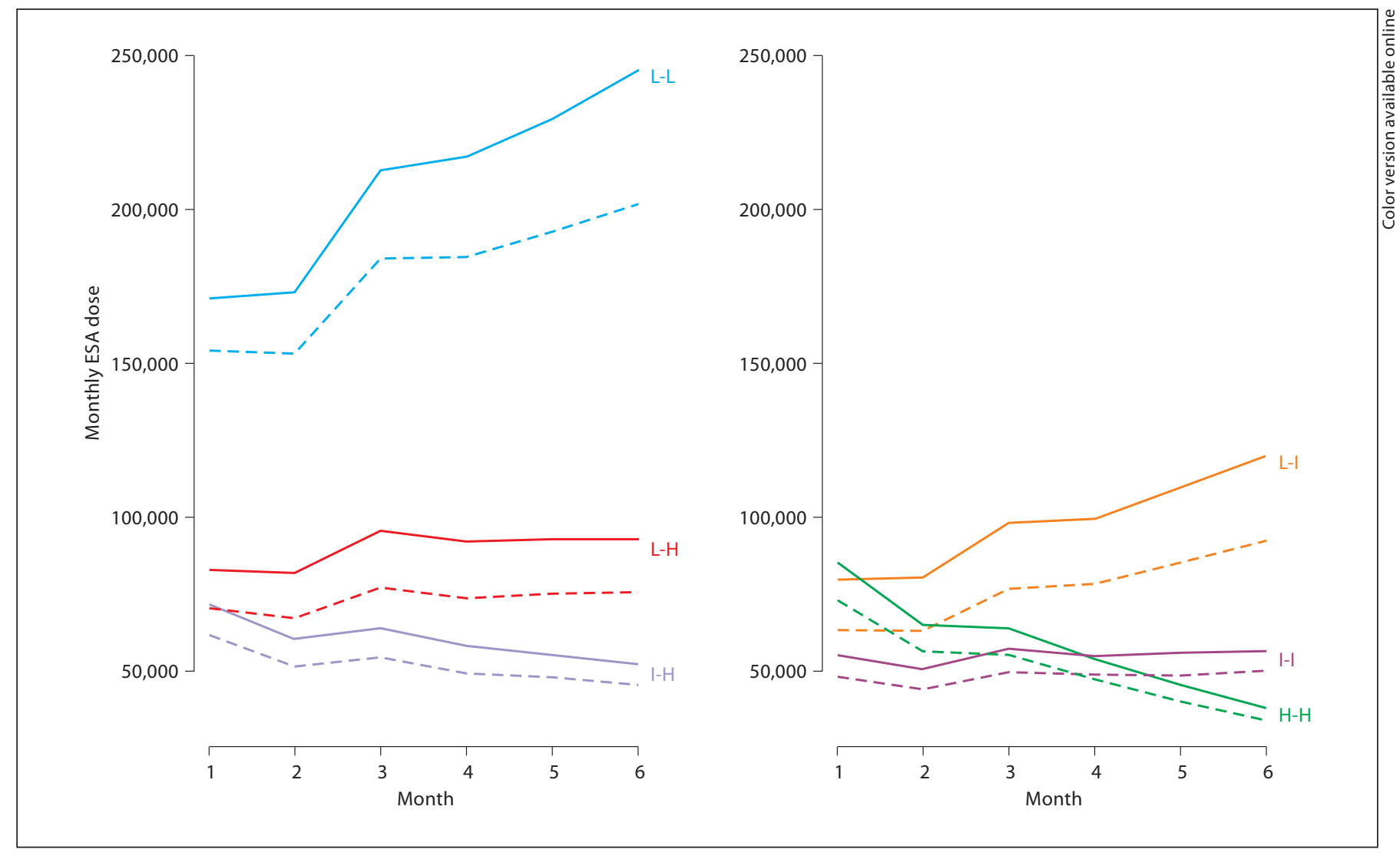

Fig. 2. Total average monthly erythropoiesis-stimulating agent (ESA) dose by hemoglobin variability groups, all patients (solid lines) and healthier patients (dashed lines) with no hospitalizations, vascular access insertions, or complications during the exposure assessment period. Monthly hemoglobin values were categorized as low $(\mathrm{L},<11 \mathrm{~g} / \mathrm{dl})$, intermediate (I, $11-12.5 \mathrm{~g} / \mathrm{dl})$, and high $(\mathrm{H},>12.5 \mathrm{~g} / \mathrm{dl})$; variability groups were classified on the basis of the lowest and highest categories seen in the 6-month observation period.

moglobin levels. Doses were lowest and most consistent for patients with hemoglobin levels consistently within the 11-12.5 g/dl range. The relationship between transfusion use and variability group was also not surprising; transfusion rates were higher for patients with hemoglobin levels of $<11 \mathrm{~g} / \mathrm{dl}$ over more months. Perhaps more surprising was the relationship between variability group and i.v. iron administration. Patients with consistently high hemoglobin levels received the highest iron doses initially, while patients in the L-L, L-I, or I-I groups received the lowest iron doses initially. As our data do not contain information on measures of iron stores (transferrin-iron saturation percentage, ferritin), it is unclear whether these relationships reflect appropriate intravenous iron use, or if improvement is necessary. However, even if iron measures suggest adequate iron stores, patients with functional (rather than absolute) iron defi- ciency can achieve increased erythropoiesis with iron administration. In the absence of evidence of active infection, recommendations generally suggest administration of low-dose maintenance iron regimens [19-21], not iron repletion, which has previously been shown to be associated with hemoglobin cycling [11].

Our previous analyses also showed that patient factors, including hospitalizations and other intercurrent events, were strongly correlated with specific variability groups, particularly the groups with hemoglobin levels consistently $<11 \mathrm{~g} / \mathrm{dl}$ or fluctuating between target levels and $<11 \mathrm{~g} / \mathrm{dl}$, and the groups with the most variability [12], in particular, precipitously falling hemoglobin levels [14]. An important clinical question relates to how much hemoglobin variability is modifiable (through changes in ESA or iron dosing or both), and how much is a consequence of underlying clinical status and thus beyond 


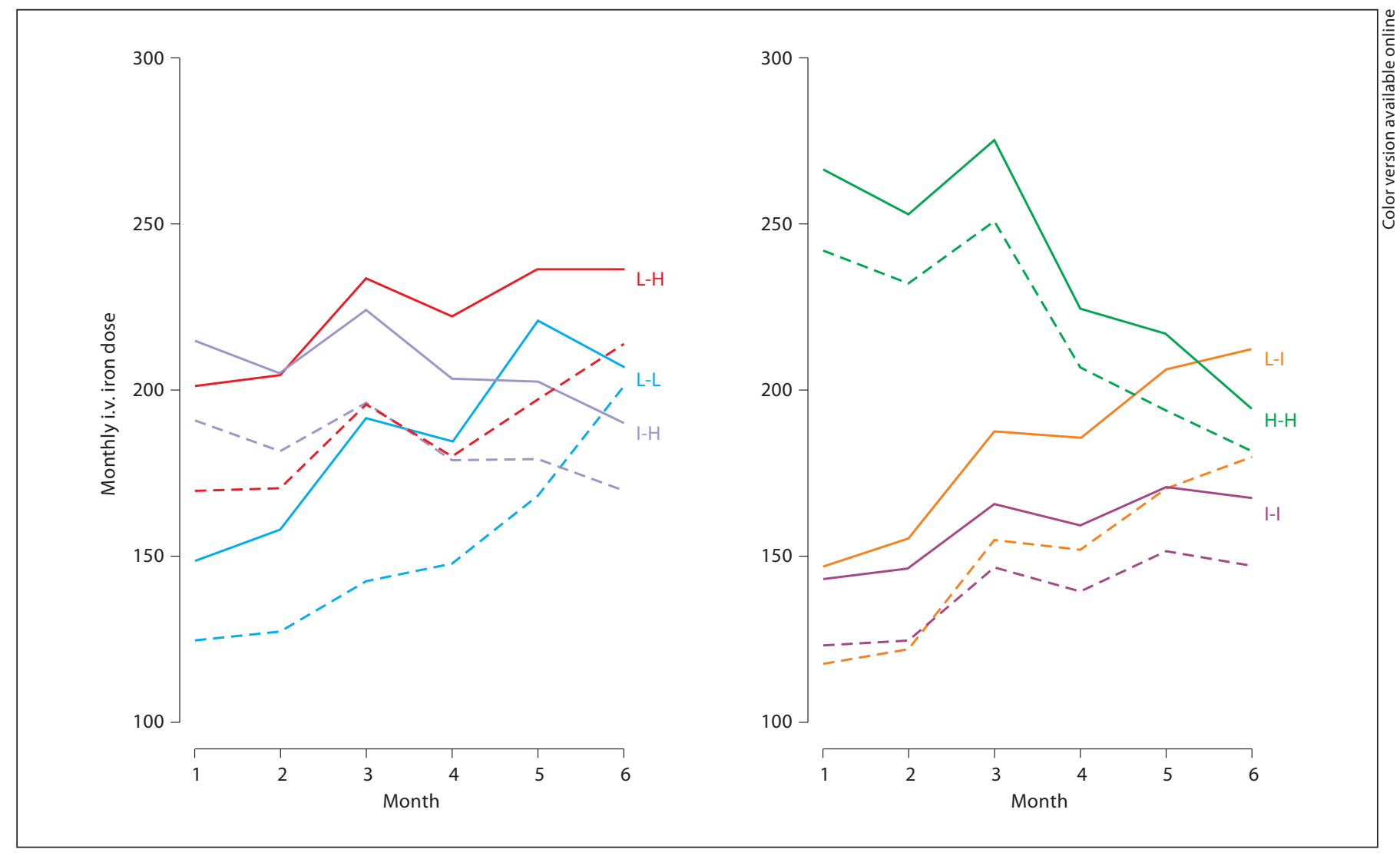

Fig. 3. Total average monthly intravenous (i.v.) iron dose (mg) by hemoglobin variability group, all patients (solid lines) and healthier patients (dashed lines) with no hospitalizations, vascular access insertions, or complications during the exposure assessment period. Monthly hemoglobin values were categorized as low ( $\mathrm{L},<11$ $\mathrm{g} / \mathrm{dl})$, intermediate $(\mathrm{I}, 11-12.5 \mathrm{~g} / \mathrm{dl})$, and high $(\mathrm{H},>12.5 \mathrm{~g} / \mathrm{dl})$; variability groups were classified on the basis of the lowest and highest categories seen in the 6-month observation period.

physicians' control. In this analysis, when we excluded patients who experienced clinical events (about 69\%), the comorbidity burden was significantly reduced, and the proportion of remaining patients with low hemoglobin patterns decreased (1.4 to $0.7 \%$, L-L; 18.3 to $16.5 \%$, L-I; and 40.2 to $31.1 \%, \mathrm{~L}-\mathrm{H}$ ), suggesting that changing clinical status may influence hemoglobin variability patterns, specifically those most strongly associated with subsequent clinical risk. Excluding these patients also influenced average monthly ESA and iron doses, which dropped across all groups, with the largest changes in the persistently low and transiently low hemoglobin level groups, shown to have the highest mortality risk in our previous analysis [14]. More marked relative reductions were observed for transfusions, though the magnitude was less pronounced as the transfusion burden in the overall population was low $(<10 \%)$. These findings sug- gest that underlying clinical status is an important factor influencing lower achieved hemoglobin levels, especially in the presence of high ESA doses (hyporesponsiveness) $[18,22,23]$. Interestingly, however, the decreased ESA and iron doses in the healthier population, and the smaller percent of patients undergoing transfusions, remained parallel to the overall population, implying that some of the variability may be explained by anemia management practices.

Our study has some potential limitations. We selected a population of hemodialysis patients who survived for 6 months, possibly affecting the generalizability of the findings. As the current mortality rate for hemodialysis patients is approximately 22 per 100 person-years (22\%), the 6-month survival requirement likely excluded very sick patients and, consequently, information on their anemia management. We also excluded patients with 




Fig. 4. Monthly percent of patients receiving transfusions by hemoglobin variability groups, all patients (solid lines) and healthier patients (dashed lines) with no hospitalizations, vascular access insertions, or complications during the exposure assessment period. Monthly hemoglobin values were categorized as low ( $\mathrm{L},<11 \mathrm{~g} / \mathrm{dl}$ ), intermediate (I, $11-12.5 \mathrm{~g} / \mathrm{dl})$, and high $(\mathrm{H},>12.5 \mathrm{~g} / \mathrm{dl})$; variability groups were classified on the basis of the lowest and highest categories seen in the 6-month observation period.

ESA doses withheld in any of the 6 months, who are likely healthier patients. Despite this, our analysis included nearly 160,000 patients, or approximately $50 \%$ of the entire US hemodialysis population. Medicare claims data provide only one reported hemoglobin level in a billing period; more granular information may provide more insight into anemia management practices within variability groups. Medicare data do not contain laboratory information, including albumin and iron measures, and we were unable to evaluate whether anemia dosing practices, particularly decisions to administer intravenous iron, were clinically indicated. Injectable medications (ESAs and iron) are not separately reported in the hospital setting, possibly resulting in underestimation of total monthly ESA dosing and iron use, a form of information bias $[23,24]$ when evaluating dosing in the outpatient setting. Finally, this is a cross-sectional study examining anemia management practices within hemoglobin variability groups, overall and limited to healthier patients, defined during the same period. It therefore does not address questions about the direction of association. For example, does being healthier reduce hemoglobin variability, or does reduced variability lead to improved health?

Anemia management protocols that include recommendations for coordinated administration of ESAs and iron may be needed (e.g., considering iron dosing in the context of hemoglobin levels). Variability in hemoglobin levels is common, and some variability is outside the control of nephrologists and dialysis facilities due to patient hospitalizations and intercurrent events. With more recent concern over large ESA doses and higher hemoglobin levels $[25,26]$, determining optimal anemia management strategies with ESAs and iron is increasingly important. 


\section{Acknowledgments}

The authors thank Chronic Disease Research Group colleagues Shane Nygaard, BA, for manuscript preparation, Nan Booth, MSW, MPH, for manuscript editing, and Stephan Dunning, MGIS, for detailed project management.

\section{Conflicts of Interest}

This study was supported by a research contract from Amgen Inc., Thousand Oaks, Calif., USA. The contract provides for the investigators of the Minneapolis Medical Research Foundation to have the final determination of the content of this publication. The data used for this study were independently acquired from the Centers for Medicare \& Medicaid Services under data use agreements with the Minneapolis Medical Research Foundation; acquisition complied with all Privacy Act requirements for confidentiality of the beneficiary-specific information. Standard fees for access to the data were paid to the Centers for Medicare \& Medicaid Services. Y.P. and J.P.E. have no conflicts of interest. They were directly responsible for the data set construction, analytical methods, SAS code, production of tables and figures, and review of the interpretation of the results. D.T.G. and A.J.C. have received consulting fees from Amgen. They were involved in the overall study design, review of the results, and drafting the manuscript. B.D.B. works in the Department of Biostatistics \& Epidemiology at Amgen; he was involved in the overall study design, review of the results, and review of the manuscript.

\section{References}

$\checkmark 1$ Ma J, Ebben J, Xia H, Collins A: Hematocrit level and associated mortality in hemodialysis patients. J Am Soc Nephrol 1999;10:610619.

-2 Kausz AT, Solid C, Pereira BJ, Collins AJ, St Peter W: Intractable anemia among hemodialysis patients: a sign of suboptimal management or a marker of disease? Am J Kidney Dis 2005; 45:136-147.

-3 Ofsthun N, Labrecque J, Lacson E, Keen M, Lazarus JM: The effects of higher hemoglobin levels on mortality and hospitalization in hemodialysis patients. Kidney Int 2003;63: 1908-1914.

-4 Robinson BM, Joffe MM, Berns JS, Pisoni RL, Port FK, Feldman HI: Anemia and mortality in hemodialysis patients: accounting for morbidity and treatment variables updated over time. Kidney Int 2005;68:23232330.

5 Regidor DL, Kopple JD, Kovesdy CP, Kilpatrick RD, McAllister CJ, Aronovitz J, Greenland S, Kalantar-Zadeh K: Associations between changes in hemoglobin and administered erythropoiesis-stimulating agent and survival in hemodialysis patients. J Am Soc Nephrol 2006;17:1181-1191.

-6 Volkova N, Arab L: Evidence-based systematic literature review of hemoglobin/hematocrit and all-cause mortality in dialysis patients. Am J Kidney Dis 2006;47:24-36.

$\checkmark 7$ Eschbach J, Abdulhadi MBJ, Delano B, Downing M, Egrie J, Evans R, Friedman E, Graber S, Haley R, Korbet S, Krantz S, Lundin A, Nissenson A, Ogden D, Paganini E, Rader B, Rutsky E, Stivelman J, Stone W, Teschan P, Van Stone J, Van Wyck D, Zuckerman K, Adamson J: Recombinant human erythropoietin in anemic patients with endstage renal disease. Results of a Phase III multicenter clinical trial. Ann Intern Med 1989;111:992-1000.
8 Epogen (package insert). Thousand Oaks, Amgen, 2008.

9 US Renal Data System: USRDS 2007 Annual Data Report: Atlas of Chronic Kidney Disease and End-Stage Renal Disease in the United States. Bethesda, National Institutes of Health, National Institute of Diabetes and Digestive and Kidney Diseases, 2007.

10 Lacson E Jr, Ofsthun N, Lazarus JM: Effect of variability in anemia management on hemoglobin outcomes in ESRD. Am J Kidney Dis 2003;41:111-124.

-11 Fishbane S, Berns JS: Hemoglobin cycling in hemodialysis patients treated with recombinant human erythropoietin. Kidney Int 2005;68:1337-1343.

12 Ebben JP, Gilbertson DT, Foley RN, Collins AJ: Hemoglobin level variability: associations with comorbidity, intercurrent events, and hospitalizations. Clin J Am Soc Nephrol 2006;1:1205-1210.

13 Yang W, Israni RK, Brunelli SM, Joffe MM, Fishbane S, Feldman HI: Hemoglobin variability and mortality in ESRD. J Am Soc Nephrol 2007; 18:3164-3170.

${ }_{14}$ Gilbertson DT, Ebben JP, Foley RN, Weinhandl ED, Bradbury BD, Collins AJ: Hemoglobin level variability: associations with mortality. Clin J Am Soc Nephrol 2008;3: 133-138.

15 Ishani A, Solid CA, Weinhandl ED, Gilbertson DT, Foley RN, Collins AJ: Association between number of months below K/DOQI haemoglobin target and risk of hospitalization and death. Nephrol Dial Transplant 2008;23:1682-1689.

16 Hebert PL, Geiss LS, Tierney EF, Engelgau MM, Yawn BP, McBean AM: Identifying persons with diabetes using Medicare claims data. Am J Med Qual 1999;14:270-277.
17 Collins AJ, Ebben JP, Gilbertson DT: EPO adjustments in patients with elevated hemoglobin levels: provider practice patterns compared with recommended practice guidelines. Am J Kidney Dis 2007;49:135142.

18 Kilpatrick RD, Critchlow CW, Fishbane S, Besarab A, Stehman-Breen C, Krishnan M, Bradbury BD: Greater epoetin alfa responsiveness is associated with improved survival in hemodialysis patients. Clin J Am Soc Nephrol 2008;3:1077-1083.

19 Agarwal R: Overcoming barriers that inhibit proper treatment of anemia. Kidney Int 2006;69(suppl 101):S9-S12.

20 Besarab A: Resolving the paradigm crisis in intravenous iron and erythropoietin management. Kidney Int Suppl 2006;101:S13S18.

21 Coyne D: Iron indices: what do they really mean? Kidney Int Suppl 2006;101:S4-S8.

22 Rossert J, Gassmann-Mayer C, Frei D, McClellan W: Prevalence and predictors of epoetin hyporesponsiveness in chronic kidney disease patients. Nephrol Dial Transplant 2007;22:794-800.

23 Bradbury BD, Wang O, Critchlow CW, Rothman KJ, Heagerty P, Keen M, Acquavella JF: Exploring relative mortality and epoetin alfa dose among hemodialysis patients. Am J Kidney Dis 2008;51:62-70.

24 Suissa S: Immortal time bias in pharmacoepidemiology. Am J Epidemiol 2008; 167: 492-499.

25 Singh AK, Szczech L, Tang KL, Barnhart H, Sapp S, Wolfson M, Reddan D: Correction of anemia with epoetin alfa in chronic kidney disease. N Engl J Med 2006;355:2085-2098.

26 Drueke TB, Locatelli F, Clyne N, Eckardt KU, Macdougall IC, Tsakiris D, Burger HU, Scherhag A: Normalization of hemoglobin level in patients with chronic kidney disease and anemia. N Engl J Med 2006;355:20712084. 